eISSN 2444-7986

DOI: http://dx.doi.org/10.14201/orl201672.14195

Caso clínico

\title{
DUPLICIDAD PARCIAL DE LA VENA YUGULAR INTERNA Y SU RELACIÓN CON EL NERVIO ESPINAL. DESCRIPCIÓN DE DOS CASOS
}

\section{Partial duplication of the internal yugular vein and its relation with the espinal nerve. Description of two cases}

\section{Luis Miguel TORRES-MORIENTES; Ana SÁNCHEZ-MARTÍNEZ; Ana FERNÁNDEZ- RODRÍGUEZ; José Ignacio BENITO-OREJAS; Jesús BACHILLER-ALONSO; Darío MORAIS- PÉREZ}

Hospital Clínico Universitario de Valladolid. Servicio de ORL y Patología Cérvico-Facial. Valladolid. España.

Correspondencia: luismitorres27@yahoo.es

Fecha de recepción: 30 de marzo de 2016

Fecha de aceptación: 25 de abril de 2016

Fecha de Publicación: 30 de abril de 2016

Conflicto de intereses: Los autores declaran no tener conflictos de intereses

Imágenes: Los autores declaran haber obtenido las imágenes con el permiso de los pacientes

Política de derechos y autoarchivo: se permite el autoarchivo de la versión post-print (SHERPA/RoMEO)

Licencia CC BY-NC-ND. Licencia Creative Commons Atribución-NoComercial-SinDerivar 4.0 Internacional

(c) Universidad de Salamanca. Su comercialización está sujeta al permiso del editor

\begin{abstract}
RESUMEN Introducción y objetivo: La duplicación de la vena yugular interna es un hallazgo raro y es diagnosticada en la mayoría de los casos de forma incidental durante la disección cervical. Descripción: Presentamos dos casos de duplicidad parcial unilateral de la vena yugular interna identificadas durante la disección cervical en dos pacientes con carcinomas laríngeos. Discusión: La vena yugular interna drena la sangre de la cavidad craneal. La duplicación puede ser unilateral, bilateral, parcial o total. En algunos casos es debido al paso de estructuras nerviosas originando una vena duplicada con una rama anterior y otra posterior. Conclusiones: La duplicidad de la vena yugular interna es una entidad muy rara pero hay que tenerla presente en la cirugía cervical, la interpretación de las angiografías y la colocación de las vías centrales.
\end{abstract}

PALABRAS CLAVE disección del cuello; nervio accesorio

SUMMARY

Introduction and objective: Duplication of internal jugular vein is a rare finding and, in most cases, it is diagnosed incidentally in the neck dissection. Description: We present two cases of unilateral partial duplication of the internal jugular vein after neck dissection in two patients with laryngeal carcinomas. Discussion: The internal jugular vein drains the blood of cranial cavity. Duplication can be unilateral, bilateral, partial or total. In some cases it is due to the passage of nerve structures causing a duplicate vein with an anterior and posterior branch. Conclusions: Duplication of internal jugular vein is a rare entity, but it is necessary to remember its existence in neck surgery, when reading angiograms and when placing central catheters. 


\section{INTRODUCCIÓN}

La vena yugular interna es la principal vena que recoge la sangre de la cavidad craneal. La duplicidad o fenestración yugular total o parcial es un hallazgo incidental infrecuente [1], más probable en las arterias craneofaciales (arteria basilar, vertebral, cerebrales y carótida interna) [2]. La incidencia se encuentra en torno a 4 casos por cada 1000 disecciones de cuello. Su presencia es trascendental ya que la vena yugular es una de las referencias cervicales pudiendo ocasionar diagnósticos erróneos y dificultades en la colocación de vías venosas centrales [3].

La duplicidad de la vena yugular interna puede presentarse aislada o afectar a pares craneales como el nervio espinal. Grant en 1951 ya describió la relación variable entre la vena yugular interna y el nervio espinal. En un $70 \%$ de los casos el nervio cruza a la vena anteriormente, en un $30 \%$ el cruce es posterior y, excepcionalmente, el nervio pasa entre la duplicidad venosa [4].

\section{DESCRIPCIÓN}

Presentamos dos casos de duplicidad parcial de la vena yugular interna hallados de forma casual durante la disección cervical.

\section{Caso 1.}

Varón de 76 años de edad con antecedentes de bronquitis crónica y enfisema e intervenido de carcinoma de tráquea en 2010 a quien le fue realizada traqueotomía y exéresis del segundo y tercer anillo traqueales en bloque con el tumor. Posteriormente fue tratado con radioterapia adyuvante. A los cinco años presentó un segundo tumor localizado en hemilaringe izquierda (estadio III; T3NOMO). Se realizó laringectomía total y vaciamiento cervical funcional ganglionar izquierdo y fistuloplastia fonatoria primaria.

En la cirugía se observó duplicidad parcial de la vena yugular interna izquierda en el tercio superior no informada en la tomografía computarizada (TC) (Figura 1). Durante el postoperatorio el paciente presentó fístula faringocutánea y se colocó un tubo de derivación salival de Montgomery. A los pocos días, tras la retirada del tubo, fue dado el alta sin fístula salival.

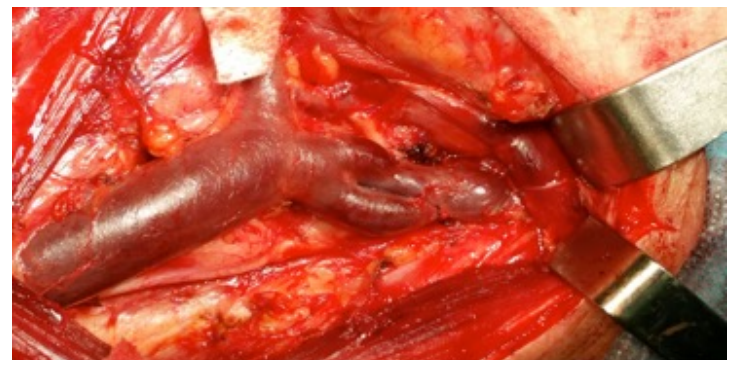

Figura 1. Vaciamiento cervical funcional ganglionar izquierdo. Duplicidad parcial de la vena yugular interna izquierda en el tercio superior y el cruce del nervio espinal lateral a la fenestración.

\section{Caso 2.}

Varón de de 75 años de edad intervenido de un carcinoma faringolaríngeo (estadio IVa) a quien se realizó vaciamiento cervical radical modificado izquierdo con laringectomía total y faringectomía parcial izquierda.

En la cirugía se observó duplicidad parcial del tercio superior de la vena yugular interna y cruce del nervio espinal izquierdo a través de la fenestración (Figura 2). En las imágenes del corte axial de la TC se aprecia la duplicidad unilateral izquierda (Figura 3).

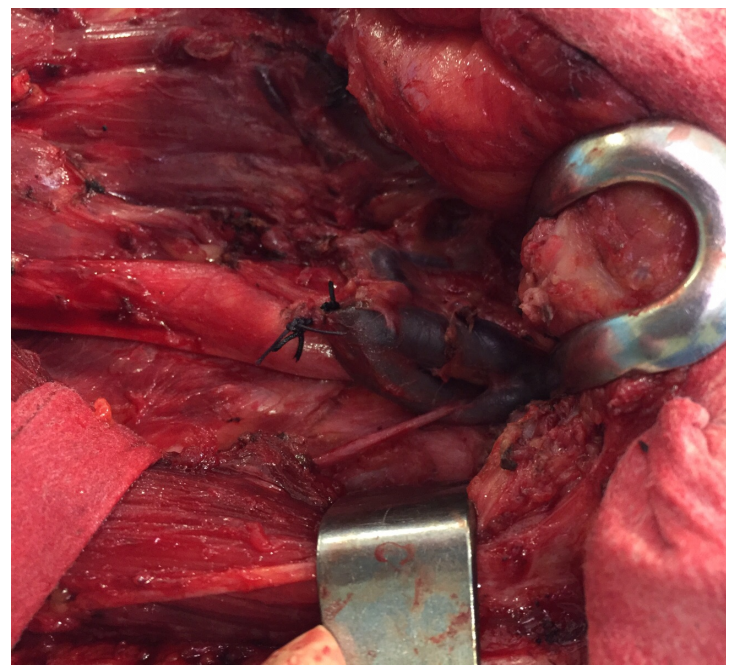

Figura 2. Vaciamiento radical modificado izquierdo con ligadura de la vena yugular interna izquierda debajo de la fenestración. Se observa una duplicidad parcial superior izquierda con cruce del nervio espinal a través de la duplicidad. 


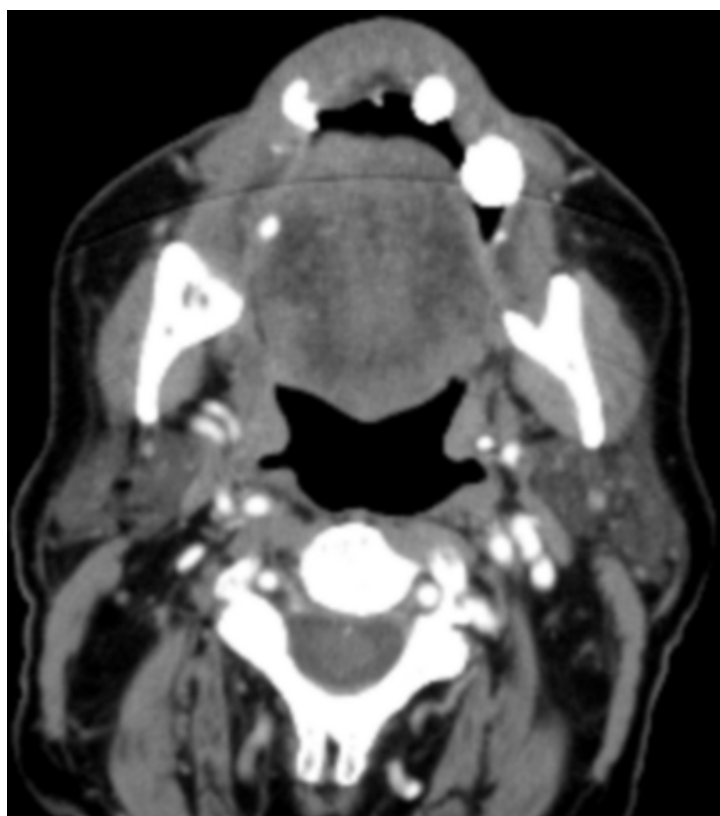

Figura 3. Corte axial de TC donde se observa la duplicidad de la vena yugular interna izquierda.

\section{DISCUSIÓN}

La vena yugular interna es el principal colector que recoge el retorno venoso de la cavidad craneal, región facial y cervical anterior. Se origina en el seno sigmoide y sale por la base del cráneo a través del foramen yugular (agujero rasgado posterior), recorre la región cervical hasta unirse con la vena subclavia dando origen al tronco venoso braquiocefálico [2]. A través del foramen yugular discurren la vena yugular interna y los pares craneales bajos (IX, $\mathrm{X}$ y XI) $[5,6]$.

La fenestración o duplicación de la vena yugular interna es un hallazgo inusual siendo muy pocos los casos publicados, según algunos estudios se encuentra en un $0,4 \%$ de la población [7].

La duplicación suele afectar al tercio superior de la vena yugular interna aunque puede hallarse en otros niveles. La relación de la duplicación y la rama lateral del nervio espinal suele ser constante, lo habitual es que el nervio pase entre la división venosa dejando medialmente la vena anterior y lateralmente la vena posterior. No siempre ocurre esto, como observamos en uno de los casos presentados donde el nervio pasa lateralmente a la duplicación venosa. El hallazgo de estas variaciones anatómicas tiene implicaciones prácticas en la cirugía cervical [7]. Además de la rama lateral del nervio espinal, otras estructuras como la arteria subescapular y las ramas anteriores del segundo y tercero nervios raquídeos, pueden pasar a través de la duplicidad [8].

La duplicación yugular suele ser unilateral pero puede ser bilateral. También pueden ser parciales o completas [1, 9]. En ocasiones puede adoptar un aspecto de "Y» invertida visible en estudios angiográficos o TC con contraste [1, $2,10]$.

Las fenestraciones arteriales se asocian con mayor incidencia de formaciones aneurismáticas, igual que ocurre en la bifurcaciones vasculares, debido al flujo turbulento en la zona de la duplicación [11]. Las fenestraciones yugulares pueden asociarse con flebectasias (dilataciones locales fusiformes, blandas y no pulsátiles que se incrementan con las maniobras de Valsalva $[7,9,10])$ de etiología desconocida. En los casos presentados no hay ectasias asociadas

La etiología de la duplicidad es desconocida. Hay tres hipótesis; vascular, neural y ósea, siendo la teoría vascular la más aceptada. Según esta, la escasez o ausencia de la capa muscular venosa podría ser la causa [1,9].

Desde el punto de vista clínico lo habitual es que sean casos asintomáticos hallados de forma incidental, no obstante en casos excepcionales pueden aparecer algunos síntomas como disfonía, odinofagia y disfagia. Pueden debutar como tumoraciones cervicales de consistencia blanda y simular otras patologías como quistes branquiales o laringoceles [12].

\section{CONCLUSIONES}

Las duplicaciones o fenestraciones de la vena yugular interna son excepcionales y hay pocos casos publicados en la literatura. La mayoría de los casos son asintomáticos y el hallazgo suele ser incidental durante la cirugía cervical aunque puede sospecharse en las pruebas radiológicas si las hay (TC con contraste). Su presencia puede implicar también anomalías en el trayecto del nervio espinal, siendo habitual el cruce de éste a través de la duplicación. Es importante conocer esta variante no solo en la cirugía cervical sino también ante la posibilidad de llevar a cabo diagnósticos erróneos en pruebas radiológicas y al colocar vías o catéteres centrales. Pueden asociarse a flebectasias en la misma vena yugular. El enfoque terapéutico es conservador. 


\section{BIBLIOGRAFÍA}

1. Kapre M, Mangalgiri AS. Clinical importance of duplication of internal yugular vein. Indian J Otolarygol Head Neck Surg. 2012;64:386-8.

2. Towbin AJ, Kanal E. A review of two cases of fenestrated internal juyular vein as seen by CT angiography. AJNR Am J Neuroradiol. 2004;25:1433-4.

3. Coca A, Rodrigo JP. Duplicación bilateral de la vena yugular interna. Acta Otorrinolaringol Esp. 2008;59:314.

4. Setty LR. A partially double internal jugular vein and its relation to the spinal accessory nerve. J Natl Med Assoc. 1960;52:174-5.

5. Linn J, Peters F, Moriggl B, Naidich TP, Brückmann $\mathrm{H}$, Yousry I. The yugular foramen: Imaging strategy and detailed anatomy at 3T. AJNR Am J Neuroradiol. 2009;30:34-41.

6. Rubinstein D, Burton BS, Walker AL. The anatomy of the inferior petrosal signus, glossopharyngeal nerve, vagus nerve, and accessory nerve in the jugular foramen. AJNR Am J Neuroradiol. 1995;16:185-94.
7. Prades JM, Timoshenko A, Dumollard JM, Durand M, Merzougui N, Martin C. High duplication of the internal jugular vein: clinical incidence in the adult and surgical consequences, a report of three clinical cases. Surg Radiol Anat. 2002;24:129-32.

8. Downie SA, Schalop L, Maruzek JN, Savitch G, Lelonek GJ, Olson TR. Bilateral duplicated internal jugular veins: case study and literature review. Clin Anat. 2007;20:260-6.

9. Rossi A, Tortori-Donati P. Internal jugular vein phlebectasia and duplication: case report with magnetic resonance angiography features. Pediatr Radiol. 2001;31:134.

10. Som PM, Shugar JM, Sacher M, Lanzieri CF. Internal jugular vein phlebectasia and duplication: CT features. J Comput Assist Tomogr. 1985;9:390-2.

11. Sanders WP, Sorek PA, Mehta BA. Fenestracion of intracranial arteries with special attention to associatted aneurysms and other anomalies. AJNR Am J Neuroradiol. 1993;14:675-80.

12. Wong BY, Strachan DR, Loney EL. Duplication of internal jugular veins: case report. J Laryngol Otol. 2010;124:341-4. 